\title{
Electronic Cigarette Use among Youth: Impact of Media, Friends and Family
}

\author{
Sarvath Ali*, Keith King, Rebeca Vidourek, Ashley Merianos and Marepalli Rao \\ University of Cincinnati, USA
}

Submission: March 28, 2018; Published: April 26, 2018

*Corresponding author: Sarvath Ali, University of Cincinnati, USA, Email: dr.sarvath@gmail.com

Abstract

E-cigarette came into existence in 2003. One can view them as a miniature hookah. They have gained a foothold, specially, in the US market with more than 400 brands. Millions of dollars are being spent advertising e-cigarettes colorfully to attract the attention of youth. It has been observed a steeply rising trend over age and grades in experimenting with e-cigarettes with close to $50 \%$ of students in Grade 12 . The main purpose of the research is to find out what drives middle and high school students in the US to experiment with e-cigarettes and adjudge their smoking behavior in the last 30 days when they start answering their questionnaire.

Objective: To determine the factors influencing e-cigarette use among youth.

Methods: National Youth Tobacco survey (NYTS) data 2015 from CDC is used for analysis. Apart from the summary statistics, logistic regression model is used for exploration of causation.

Results: Significant increase use of e-cigarettes is due to perceived peer and family approval. But advertisements on TV, movies and famous personalities smoking do not exert significant influence on youth.

Conclusion: Restricting youth-targeted advertising with glamorous images of e-cigarettes may limit the rising experimentation and use of e-cigarettes in young people. Perceived non-harm in e-cigarettes is a factor driving usage. Proper education to youth and families is necessary.

Keywords: Addiction; advertising and promotion; cessation; electronic nicotine delivery device; youth smoking.

What this paper adds: It is the first time a systematic exploration of factors influencing e-cigarette usage is pursued using a large national questionnaire survey. Factors are indeed identified.

What is already known: Rising trend in e-cigarette usage among youth over the years 2011-2015 has been documented. Factors have been identified for e-cigarette usage following an online small survey. There is some degree of corroboration between this study and our study.

\section{Introduction}

Since last decade electronic cigarettes (e-cigarettes) are becoming popular and have been progressively marketed in the USA. E-cigarette smoking trend is rising steeply. Out of 45 million smokers in the USA, 3 million are e-cigarette smokers (CDC Website). E-cigarette was first patented in China in 2003 [1] and introduced into the U.S. markets in 2007 [1,2]. Currently, an extensive range of e-cigarettes, more than 400 brands, are available in the open market. It is readily available online to youth irrespective of their age. Youth-targeted advertising with dazzling images of e-cigarettes has piqued curiosity among young people, leading to experimentation with e-cigarettes.

According to many epidemiological studies, e-cigarettes are most frequently utilized by the current smokers for experimentation as well as a helpful tool to quit smoking. They are perceived to be healthier than traditional cigarette smoking. The effectiveness of e-cigarettes as a smoking cessation aid is unknown. However, Food and Drug Administration (FDA) have been attempting to regulate the sale of e-cigarettes, claiming that they are unauthorized drug delivery devices. In 2010, the U.S. Court of Appeals ruled that e-cigarettes should be regulated as tobacco products unless marketed for therapeutic purposes $[3,4]$. On May 5, 2016, Mitch Zeller, director of the FDA Center for Tobacco Products stipulated during a media briefing: "Not allowing products to be sold to persons under the age of 18 years (both in person and online); Requiring age verification by photo ID; Not permitting the sale of covered tobacco products in vending machines (unless in an adult-only facility); and Not allowing the distribution of free samples." The rules also include other alternative forms of tobacco like cigars, hookah tobacco and pipe tobacco [5]. As the risk factors of e-cigarette are similar to conventional cigarettes, preventive policies are needed to protect the health of youth. Among the youth, especially, in older age groups, awareness of e-cigarettes and experimentation are acutely observable [6]. E-cigarette use is expected to increase progressively. More efforts are required to bridge the gaps in 
e-cigarettes centered research to promote better evaluation, reduce risks and health effects, develop ways to regulation of sale and curb marketing and advertisements worldwide. From a public health perspective, proper interventions for the focus groups are highly recommended.

\section{Literature Review}

\section{Theoretical Framework and Conceptualization}

The theory, diffusion of innovation, suggests that adoption of new technology might be faster so that the change expresses certain key features; Innovations that spreads quickly have a practical benefit over the things they are replacing, for example, the cost of e-cigarettes is less than the regular cigarettes. Also, innovations which are popular may be compatible with values and experiences desires to adoption because e-cigarettes resemble and feel like a regular cigarette. Youth respond differently to the advertisements depends on how they compare the innovative product e-cigarette with a traditional cigarette $[7,8]$.

In an analysis of 12 United Kingdom and Scottish newspapers and three most popular online news resources between 2007 and 2012 on e-cigarette advertisements, five themes emerged; "getting around smoke-free legislation; risk and uncertainty; healthier choice; celebrity use; and price." By pinning the diffusion of innovations theory, authors suggest that newspaper advertisement of e-cigarettes offer youth with relevant information about what e-cigarettes are, how they work, and their virtual advantages and their cost effectiveness. Advertisements showing pictures of celebrities smoking e-cigarettes meaning a celebrity promotes an e-cigarette brand. Numerous comparative advantages over regular smoking were emphasized, for example, e-cigarettes are healthier, cheaper, not covered by smokefree legislation, and used by celebrities [9].

\section{Relative Importance of Peers and Parents}

Bandura's Social learning theory (SLT) $[10,11]$ suggests that actions, perceptions of behavior, and atmosphere interact to influence one another. Adolescents view favorably smoking models in their surroundings. The presence of smoking patterns in a person's social circle would promote an atmosphere of tolerance for smoking $[10,11]$. At the beginning, in a child's life, perhaps, parents are the primary influence. Later, as the child grows into adulthood, parental influence declines and social influence dominates as much of the time is then spent with friends and that they may bond due to sharing of commonality such as the stress of adolescence. Particularly, on smoking and other habits like drugs, friends are of greater influence than parents [12]. Other factors like personality have been shown to interrelate with their environment in predicting smoking. For example, low level respect to parents and teachers with high rebelliousness in schools may be influenced by friends smoking and involved in antisocial behavior $[13,14]$.
Parental and sibling smoking may also promote smoking among children and youth. Parental approval plays a significant role of adolescent smoking. In Hispanic and Asian communities, families live intimately very close to each other. Parents have control over their children and watch their activities. Offspring also respect their parents and elders. Hispanic youth is more likely than other young people to be protected from secondhand smoke by smoking bans at home. Seventy-one percent of all Hispanic households do not allow smoking inside home. Perceived parental disapproval of smoking is a protective factor against adolescent smoking [15].

Other factors like low socioeconomic status, lack of parental support or involvement, accessibility, availability of smoking products, low level of academic achievement, low self-image, and aggressive behavior are associated with youth smoking [16]. Peer pressure is a major factor in their decision-making process. Several studies show that the influence of peer is especially powerful in determining when and how young people first try cigarettes. Whatever someone thinks that their child is smart, all children and adolescents are vulnerable either to negative or positive influence. The smoking rate among children and young adults who have three or more friends who smoke are ten times higher than those who report that none of their friends smoke [17].

\section{Divided Opinion by Researchers}

It is felt by many that e-cigarettes to be harmless than traditional cigarettes. However, a lot of the devices contain nicotine and inhaling their vapors exposes users to toxic substances, including lead, cadmium, and nickel, heavy metals that are linked with significant health problems $[18,19]$.

\section{Marketing}

Many studies show that e-cigarette websites every so often contains unsubstantiated health claims which mislead consumers specifically youth. Propagation of e-cigarettes marketing and sales are mainly through the internet. One of the major claims is that e-cigarettes do not produce secondhand smoke and they are contemporary. The most common messages about the products are: e-cigarettes are cheaper; healthier; safer than regular cigarettes; and can be smoked anywhere indoor by avoiding smoke-free policies. There is no age restriction for shopping e-cigarettes online which leaves open room for youth to access and marketing exposure [20].

According to a study by Jennifer, et al. youth and young adults' exposure to television e-cigarette advertisements increased four folds from 2011 to 2013. Presently, cigarette companies who also manufacture e-cigarettes advertise their products on the national cable network to viewers who includes 24 million youth and young adults. If the same trend of advertising of e-cigarettes on television continues, use of e-cigarettes and its awareness are likely to increase among youth and have impact on their health [21]. 


\section{Factors Associated with Youth Tobacco Use}

Cognitive and Affective Processes: There is a strong relationship between youth tobacco use and adverse effects, such as depression, anxiety, and stress. Potentials of positive outcomes from smoking, such as coping with stress and controlling weight, are related to youth tobacco use. There is evidence that child may be sensitive to nicotine and that teens can feel dependent on nicotine sooner than adults. Genetic factors may mean that it is harder for some people to quit smoking once they have started [22].

In an experimental study, Farrelly, etal. [23] has demonstrated that Television (TV) advertisements of e-cigarette by the manufacturers NJOY and others have inspired youth in using e-cigarettes, who have never used them before. The sample is dichotomized randomly into two groups (treatment and control groups). The treatment group was exposed to four e-cigarette TV advertisements. The treatment group is significantly more likely experiment with e-cigarettes than the control group (OR=1.54, $\mathrm{p}=0.001$ ). Treatment group is more likely try an e-cigarette if a fried offered one than the control group (OR=1.29, $\mathrm{p}=0.02)$.

\section{Reported Hazards}

Recently CNN published an incidence on e-cigarette explosion in a bus which caused 3rd-degree burns (CNN Vide 2016) [24,25]. Another incident that reported a case of e-cigarette explosion: a twenty-year old man was taken to the emergency department after an electronic cigarette had exploded in his mouth causing orofacial burns and lacerations. Further evaluation by dentists showed injury to lips and gingiva and partial avulsion to complete loss of mandibular central incisors, and fractures of multiple anterior teeth.

The National Fire Protection Association (NFPA) USA, reports through news media that the incidents of electronic cigarettes resulted in injury due to explosions while smoking and or carrying them in person. All victims were ages between 17 and 35 years. There were twelve cases of e-cigarettes explosions reported during the year 2015; injuries like burns and cuts on face, severe first degree burns to face and chest, finger burns, damage to teeth and mouth. Serious devastated vertebrae, multiple fractures, broken neck, and knocked out teeth were reported. E-cigarette battery ignited in pocket causing second and third-degree burns on legs were among them. Also, e-cigarette exploded near mouth causing severe burns in mouth and hand leading to surgery of the tongue and amputation of the finger.

A study was conducted to assess young adults perceptions of electronic cigarettes and dissolvable tobacco products and to know their intentions to try those products. Participants of this study reported a positive perception of innovative products because of their flavors and easy to use even at restricted indoor areas. Their comments were that these products could be a gateway to regular tobacco smoking. In this study, discussions were conducted with eleven focus groups consisting of total 66 participants; all were college students ages between 18 and 26 years. Participants observation of these product as most modern and sleek considered to be most high-tech. About half of the participants answered yes to the question; if they would try e-cigarettes when offered by a friend.

\section{Objective}

The main goal of the study is to estimate the impact of e-cigarettes due to advertisements in media and marketing on youth. In addition, we want to examine the impact of household smoking, parents, siblings, and friends on youth experimenting and smoking e-cigarettes. We also focus on knowledge, attitude, and behavior among youth about e-cigarette smoking.

\section{Research Questions}

a) Do friends promote e-cigarette use and smoking?

b) Does recent e-cigarette use (past 30 days) depend significantly on media advertisement for e-cigarettes?

c) Does the use of e-cigarette and smoking by family members and friends raise the possibility of smoking by youth?

d) Are there significant differences in experimenting and smoking e-cigarettes across races, gender, and age?

\section{Data Source}

Data from National Youth Tobacco Survey (NYTS) from the year 2015 is used. The objective of NYTS survey was to seek knowledge on a whole range of issues on e-cigarette smoking among the national population of public and private middle and high school students. A nationally representative sample of middle school and high school students from all 50 states and the District of Columbia was chosen. A questionnaire was given to the participants of the survey to complete using pencil and later scanned to computer. In the year 2015, a final sample of 255 schools was selected out of which 185 schools participated $(\mathrm{n}=17,711)$. The overall participation rate for the year 2015 was $77 \%$.

\section{Survey Instrument}

The questionnaire of 2015 included a total number of 81 questions. For our study, we selected questions: Have you ever used an e-cigarette even once or twice in life time; Have you used e-cigarettes on one or more days in the past 30 days; If one of your best friends were to offer you an electronic cigarette, would you use it; Does any person who lives with you now use e-cigarettes; What are the reasons why you have used e-cigarettes; When you watch TV, how often do you see advertisements or promotions for e-cigarettes (NYTS 2015).

\section{Results}

Using R software, we have performed logistic regression and calculate odds ratio to determine how significant the factors, age, 
sex, friends, family and media are. The two responses are: recent use of e-cigarettes and experimenting with e-cigarettes in the past. Regarding gender, males have tried e-cigarettes significantly more than females. There are more or less equal number of males and females in the middle and high school. Twenty-nine percent of males and twenty-four percent of females have tried e-cigarettes. The difference is significant $(\mathrm{OR}=1.92 ; \mathrm{p}$-value $=$ 0.001). Experimenting with e-cigarettes is not sustained into habitual smoking if behavior in the last 30 days is taken as an indicator (Table 1). As age rises, incidence of experimenting with e-cigarettes rises steeply as indicated by the rises in the Odds

Table 1: Adjusted Odds Ratio for use of e-cigarette smoked sometime in the past at least once or more, smoked e-cigarettes in the last 30 days and demographic characteristics.
Ratios (Table 2). Seven percent of pupils in the age group 9-11 years, sixteen percent in the age group 12-14 years, thirty-seven percent in the age group 15-17 years, and forty-five percent in the age group 18-19 years. have experimented with e-cigarettes in the past. The rise in the percentages is steepest from the age group 12-14 years to 15-17 years. As per the current behavior of smoking, three percent of pupils in the age group 9-11 years smoked at least one a day in the past 30 days. The percentages are six, fifteen, and twenty-one in the age groups 12-14, 15-17, and $18-19$, respectively.

\begin{tabular}{|c|c|c|}
\hline & $\begin{array}{c}\text { Smoked e-Cigarette Sometime in the Past at } \\
\text { Least Once }\end{array}$ & $\begin{array}{c}\text { Smoked e-Cigarette Sometime in the Past } \\
30 \text { Days at Least One Day }\end{array}$ \\
\hline & Adjusted OR (95\%CI) & Adjusted OR (95\%CI) \\
\hline \multicolumn{3}{|l|}{ Sex } \\
\hline Male & $1.83(1.62,2.07)$ & $1.92(1.68,2.21)$ \\
\hline Female (baseline) & 1 & 1 \\
\hline \multicolumn{3}{|l|}{ Age } \\
\hline 9-11 years old (Base line) & 1 & 1 \\
\hline 12-14 years' old & $2.17(1.41,3.41)$ & $1.17(0.72,1.96)$ \\
\hline 15-17 years' old & $5.12(3.34,8.03)$ & $2.17(1.41,3.40)$ \\
\hline 18-19 years' old & $7.39(4.67,11.95)$ & $5.11(3.34,8.03)$ \\
\hline \multicolumn{3}{|l|}{ Race } \\
\hline Mexican & $1.21(1.03,1.44)$ & $0.88(0.73,1.05)$ \\
\hline Not Mexican (baseline) & 1 & 1 \\
\hline Puerto Rican & $1.05(0.74,1.48)$ & $1.33(0.93,1.88)$ \\
\hline Not Puerto Rican (baseline) & 1 & 1 \\
\hline Cuban & $1.58(0.99,2.48)$ & $1.63(1.29,2.64)$ \\
\hline Not Cuban (baseline) & 1 & 1 \\
\hline Spanish & $1.13(0.91,1.38)$ & $0.99(0.79,1.25)$ \\
\hline Not Spanish(baseline) & 1 & 1 \\
\hline Alaska Native & $1.02(0.75,1.29)$ & $1.08(0.84,1.40)$ \\
\hline Not Alaska Native & 1 & 1 \\
\hline Asian & $0.69(0.50,0.92)$ & $0.65(0.46,0.91)$ \\
\hline Not Asian & 1 & 1 \\
\hline African American & $0.90(0.75,1.10)$ & $0.84(0.68,1.04)$ \\
\hline Not African American & 1 & 1 \\
\hline Native Hawaiian & $1.76(1.25,2.45)$ & $1.85(1.23,2.64)$ \\
\hline Not Native Hawaiian & 1 & 1 \\
\hline White & $0.87(0.74,1.02)$ & $1.03(0.86,1.24)$ \\
\hline Not White & 1 & 1 \\
\hline
\end{tabular}


Table 2: Contingency table.

\begin{tabular}{|c|c|c|c|c|}
\hline \multirow{2}{*}{} & \multicolumn{2}{|c|}{ e-Cigarettes Ever Tried } & Smoked e-Cigarettes at Least One-Day in Past 30 \\
Days
\end{tabular}

Regarding race, data only permits comparison between each ethnic group and the rest. Comparisons between ethnicity and the rest: Three distinct patterns emerge when it comes to experimenting with e-cigarettes.

a) Mexicans (OR > 1) and Hawaiians (OR > 1) experiment significantly with e-cigarettes than the rest.

b) Asians $(\mathrm{OR}<1)$ experiment significantly less than the rest.

c) Each of the remaining ethnicities (Whites, African Americans, Cubans, Puerto Ricans, Spanish, and Native Alaskans) exhibit no significant difference with the rest (Table 2).

When it comes to smoking on at least one day in the past 30 days, again three patterns emerge: More Cubans than the rest significantly; Less Asians than the rest significantly; No significant difference between the remaining ethnicities versus the rest (Table 2).
Impact of advertisements on Internet: When compared to the baseline not using internet, the other categories have not demonstrated a significant difference between those who smoked and who did not smoke (Tables 3 \& 4). Concerning friends offering e-cigarettes: the responses are; definitely yes; probably no; and definitely no. They are codified as $1,2,3$, and 4 , and treated as numeric. The Odds ratio 0.19 is significantly less than unity ( $p$-value $<0.001$ ). The implication is that the responses when a friend offers e-cigarette significantly vary between those who smoke and those who do not smoke. Family and friends do exert a very strong influence on smoking. TV advertisements with famous personalities and celebrities smoking: sixty-eight percent of those who smoked e-cigarettes saw e-cigarettes advertisement sometimes, most of the time, or always. The figure for those who did not smoke is $66 \%$. We can say that advertisements have no bearing in smoking behavior (Table 5). This contradicts previous research by Duke, which reports famous personalities smoking exerts significant influence between those who smoked and who did not smoke.

\section{Table 3:}

\begin{tabular}{|c|c|c|c|c|}
\hline \multicolumn{5}{|c|}{ 2x4 Contingency Table: Smoked at Least One Day in the Past 30 Days } \\
\hline Age group & 9-11 years & $12-14$ years & $15-17$ years & 18-19 years \\
\hline Did not smoke & 898 & 7398 & 6082 & 1062 \\
\hline Smoked & 36 & 510 & 1104 & 298 \\
\hline Total & 934 & 7908 & 7186 & 1360 \\
\hline Percentage & 0.3 & 0.6 & 0.15 & 0.21 \\
\hline \multicolumn{5}{|c|}{ Contingency Table: Ever Smoking VS Age } \\
\hline Age group & 9-11 years & $12-14$ years & $15-17$ years & $18-19$ years \\
\hline not smoke & 863 & 6604 & 4487 & 736 \\
\hline Smoked & 74 & 1295 & 2260 & 617 \\
\hline Total & 937 & 7899 & 7155 & 1353 \\
\hline Percentage & 0.07 & 0.16 & 0.37 & 0.45 \\
\hline
\end{tabular}

Table 4:

\begin{tabular}{|c|c|c|}
\hline \multicolumn{2}{|c|}{ When Using Internet How Often You See Adds On e-Cigarettes } \\
\hline Never see & $0.91(0.61,1.37)$ & $0.74(0.49,1.12)$ \\
\hline Rarely & $1.14(0.77,1.69)$ & $0.72(0.49,1.06)$ \\
\hline Sometimes & $1.38(0.93,2.05)$ & $0.80(0.55,1.19)$ \\
\hline Most of the time & $1.54(1.00,3.71)$ & $0.97(0.64,1.47)$ \\
\hline Always & $2.24(1.35,3.71)$ & $1.21(0.77,1.91)$ \\
\hline Do not use internet (baseline) & 1 & 1 \\
\hline
\end{tabular}




\begin{tabular}{|c|c|c|}
\hline \multicolumn{3}{|c|}{$\begin{array}{c}\text { When Watching Tv, How Often Adds on e-Cigarette Smoking by Famous Actors When You Read Newspapers and Magazines How Often } \\
\text { You See Adds on e-Cigarettes }\end{array}$} \\
\hline Never see & $0.36(0.14,1.14)$ & $0.96(0.66,1.41)$ \\
\hline Rarely & $0.35(0.13,1.11)$ & $1.07(0.75,1.55)$ \\
\hline Sometimes & $0.33(0.12,1.04)$ & $0.99(0.69,1.43)$ \\
\hline Most of the time & $0.33(0.12,1.05)$ & $0.97(0.64,1.46)$ \\
\hline Always & $0.24(0.09,0.79)$ & $1.02(0.63,1.63)$ \\
\hline Do not used TV (baseline) & 1 & 1 \\
\hline \multicolumn{3}{|c|}{ When You Read Newspapers And Magazines How Often You See Adds on e-Cigarettes } \\
\hline Never see & $1.18(0.94,1.47)$ & $1.34(0.66,1.41)$ \\
\hline Rarely & $1.20(1.01,1.42)$ & $1.51(0.75,1.55)$ \\
\hline Sometimes & $1.05(0.87,1.27)$ & $1.49(0.69,1.43)$ \\
\hline Most of the time & $1.21(0.90,1.61)$ & $1.65(0.64,1.46)$ \\
\hline Always & $1.37(0.85,2.20)$ & $1.74(0.63,1.63)$ \\
\hline Do not read newspapers (baseline) & 1 & 1 \\
\hline \multicolumn{3}{|c|}{ Perceived Harm in Using e-Cigarettes } \\
\hline Little harm & $0.80(0.68,0.95)$ & $0.91(0.77,1.07)$ \\
\hline Some harm & $0.61(0.51,0.74)$ & $0.76(0.62,0.94)$ \\
\hline $0.76(0.62,0.94)$ & $0.530 .43,0.66)$ & $0.67(0.51,0.88)$ \\
\hline No harm (baseline) & 1 & 1 \\
\hline $\begin{array}{l}\text { Friends and Family Members Smoked } \\
\text { e-cigarette }\end{array}$ & $2.14(1.74,2.63)$ & $2.80(2.96,3.32)$ \\
\hline Not smoking(baseline) & 1 & 1 \\
\hline Famous people on TV and movies use them & $4.66(2.16,10.57)$ & $3.29(1.85,5.87)$ \\
\hline Not because (baseline) & 1 & 1 \\
\hline They can be used in prohibited areas & $21.37(10.12,51.59)$ & $2.15(1.68,2.77)$ \\
\hline Not because (baseline) & 1 & 1 \\
\hline
\end{tabular}

Table 5: Influence of TV ads with famous people using e-cigarettes.

\begin{tabular}{|c|c|c|c|c|c|c|}
\hline & Do Not Watch & Never Watch & Rarely Watch & Some Watch & $\begin{array}{c}\text { Most of the } \\
\text { Watch }\end{array}$ & Always Watch \\
\hline Not smoked & $3 \%$ & $7 \%$ & $22 \%$ & $41 \%$ & $18 \%$ & $7 \%$ \\
\hline smoked & $4.5 \%$ & $6.5 \%$ & $21 \%$ & $39 \%$ & $19 \%$ & $8 \%$ \\
\hline
\end{tabular}

\section{Discussion}

This study presents results from a nationally representative sample survey of youth from private and public middle and high schools, ages between 9 and 19 years, with $n=17711$. There are more or less equal number of males and females in the middle and high schools. A number of pointers emerge from our data analysis. We found that boys have tried e-cigarettes significantly more than the girls. Twenty-four percent of females and twentynine percent of males have tried e-cigarettes. The difference is significant $(\mathrm{OR}=1.183 \mathrm{p}$-value $<0.001)$. Nine percent of females and 13 percent of males smoked at least one day in the last 30 days. The difference is again significant $(\mathrm{OR}=1.92 ; \mathrm{p}$-value $=$ 0.001 ). There is a steep significant decrease from the incidence of experimenting at least once in the past to smoking at least one day in the last 30 days. Experimenting e-cigarette smoking is not sustained into habitual smoking if the behavior in the last 30 days is taken as an indicator.

The odds of exposure to e-cigarettes are significantly affected by age. The odds of e-cigarette used at least once in the past, teenagers of 12-19 years old are double that of age group 9-11 (baseline group) (OR=2.17, 95\% CI, 1.41-3.41). The odds for the use of e-cigarette at least one day in the last 30 days was not statistically significant compared with baseline group (OR:1.17, $95 \% \mathrm{CI}=0.72-1.96$ ). The age group 18-19 years has the highest odds of both in the use of at least once in the past and at least one day in the last 30 days (OR: 7.39, 95\% CI=4.67-11.95) (OR: 5.11, $95 \% \mathrm{CI}=3.34-8.03)$. As age rises, the incidence of experimenting with e-cigarettes rises steeply as indicated by the increases in the Odds Ratio. Perception of harm in smoking e-cigarettes has an impact on those who experimented and those who did not 
(OR 0.53, 95\% CI $=0.43-0.66)$. Seventy percent of those tried e-cigarettes asserted no harm or little harm, whereas $63.5 \%$ of those who never smoked believed it has some or lot of harm.

If a friend or a family member smoked e-cigarettes, the youths are more likely to experiment (OR 2.14, 95\% CI=1.742.63) (p-value 0.001). This is in conformity with Farrelly. Ninetyfive percent of students who smoked have a family member or friend who smoked e-cigarettes. Whereas only $17 \%$ of students have no friend or family members smoking e-cigarettes, which suggests family and friends do exert a very high significance. With reference to the factors examined above, the results are similar to those observed in the previous studies. The internet advertisement increases the odds of experimentation of e-cigarettes. However, those who have never seen e-cigarette advertisements are less likely to experiment with e-cigarettes. Experimentation also depends on the frequency of seeing commercials on the internet. Compared to those who do not use the internet, subjects who always see online advertisement the odds of experimentation are OR 2.24. These findings contradict the previous findings. When compared to the baseline of not seeing and using TV, and newspapers, the other groups have not demonstrated a significant difference between those who smoked and who do not smoke e-cigarettes (OR 0.24, 95\% CI $=0.9-0.79$ ). Some of the previous studies suggest that there is a strong influence of TV advertisements showing famous personalities and celebrities smoking.

\section{Limitations}

The data used comes from surveys. There is no guarantee that answers are truthful. Since the subjects are youth, we do not expect them not to be truthful. Questions for example on harm are hard to judge with such ages. Results cannot be generalizable since survey depends on self-reporting of smoking which might have been an issue of social prestige bias.

\section{Conclusion}

In this study, the evolving trend in important factors is observed. Factors, such as peer pressure, family and friend's approval, and perceived harm belief are of great concern from public health perspective. The results can be conveyed to public health workers and policy makers to help implement tailored intervention programs. Findings from such studies have implications for both regulation and public health messaging and to prioritize investing in early prevention since smoking is a preventable habit and specially e-cigarettes are in a budding stage, it is recommended that health educators should take a lead and outreach targeted population. In summary, emphasis should be made on the following: a) Perceived harm in smoking; those who smoke rationalize that smoking causes no harm, those who do not smoke are apprehensive that it causes harm. b) Policy prescription: Target youth, especially, juniors and seniors, emphasizing harmfulness of smoking in any form. c) Family and friends smoking has a corrosive effect on health of youth. This is an issue difficult to address. Health education for the entire family may be helpful.

\section{Future Directions for Research}

We have analyzed 2015 data comprehensively. We want to extend the analysis to all other years to study evolving trend in significant factors. Further research is needed on e-cigarette smoking to investigate whether particular subpopulation or ethnicity are exposed to high risk due to marketing and advertisements.

\section{IRB}

Institutional Review board approval has been obtained from University of Cincinnati. No Animals and human are involved in this research (Data set used is freely accessible online).

\section{Refernces}

1. Bell K, Keane H (2012) Nicotine control: E-cigarettes, smoking and addiction. International Journal of Drug Policy 23(3): 242-247.

2. Regan AK, Promoff G, Dube SR, Arrazola R (2011) Electronic nicotine delivery systems: adult use and awareness of the e cigarette in the USA. Tobacco control.

3. (2017) USCIS Administrative Appeals office (AAO).

4. CDC - Fact Sheet - Youth and Tobacco Use - Smoking.

5. (2009) MedWatch: The FDA Safety Information and Adverse Event Reporting Program.

6. Farsalinos KE, Polosa R (2014) Safety evaluation and risk assessment of electronic cigarettes as tobacco cigarette substitutes: a systematic review. Therapeutic advances in drug safety 5(2): 67-86.

7. Dearing JW (2009) Applying diffusion of innovation theory to intervention development. Research on social work practice 19(5): 503-518.

8. Etter J, F Bullen C (2011) Electronic cigarette: users profile, utilization, satisfaction, and perceived efficacy. Addiction 106(11): 2017-2028.

9. Rooke C, Amos A (2014) News media representations of electronic cigarettes: an analysis of newspaper coverage in the UK and Scotland. Tobacco control 23(6): 507-512.

10. Bandura A (1977) Selfefficacy toward a unifying theory of behavioral change. Psychological review 84(2): 191-215.

11. Farrelly MC (2015) American Journal of Preventive Medicine 49(5): 686-693.

12. Ennett ST, Bauman KE, Foshee VA, Pemberton M, Hicks KA (2001) Parent Child Communication About Adolescent Tobacco and Alcohol Use: What Do Parents Say and Does It Affect Youth Behavior? Journal of Marriage and Family 63(1): 48-62.

13. Fuemmeler BF, Lloyd A, Metz AE, Brown RT (2002) Risk taking and smoking tendency among primarily African American school children: Moderating influences of peer susceptibility. Journal of clinical psychology in medical settings 9(4): 323-330.

14. Grana RA, Ling PM (2014) Smoking revolution a content analysis of electronic cigarette retail websites. American journal of preventive medicine 46(4): 395-403.

15. Mccausland K, Thomas K, Watson Stryker E, Xiao J, Green M (2005) Legacy First Look Report 14 Secondhand Smoke: Youth Exposure and Adult Attitudes. Washington DC: American Legacy Foundation. 
16. Markham WA, Lopez ML, Aveyard P, Herrero P, Bridle C, et al. (2009) Mediated moderated and direct effects of country of residence, age, and gender on the cognitive and social determinants of adolescent smoking in Spain and the UK: a cross sectional study. BMC Public Health 9(1): 173.

17. Grana RA, Ling PM (2014) Smoking revolution a content analysis of electronic cigarette retail websites. American journal of preventive medicine 46(4): 395-403.

18. Grana Benowitz, Neal MD, Glantz Stanton A (2013) Background Paper on E-cigarettes (Electronic Nicotine Delivery Systems). UC San Francisco: Center for Tobacco Control Research and Education.

19. (2017) National Youth Tobacco Survey (NYTS).

20. Robertson L, Mc Gee R, Marsh L, Hoek J (2014) A systematic review on the impact of point of sale tobacco promotion on smoking. Nicotine \& Tobacco Research pp. 168.
21. Duke JC, Lee YO, Kim AE, Watson KA, Arnold KY, et al. (2014) Exposure to electronic cigarette television advertisements among youth and young adults. Pediatrics 134(1): e29-e36.

22. Morrell HE, Cohen LM (2006) Cigarette smoking, anxiety and depression. Journal of Psychopathology and Behavioral Assessment 28(4): 281-295.

23. Richard Campbell (2016) Electronic Cigarette Explosions and Fires: The 2015 Experience.

24. Regan AK, Promoff G, Dube SR, Arrazola R (2013) Electronic nicotine delivery systems: adult use and awareness of the 'e-cigarette'in the USA. Tobacco control 22(1): 19-23.

25. Ravenel M, Neville B, Chi A (2016) Electronic Cigarette Explosion: Case Report of an Emerging Cause of Orofacial Trauma. Oral Surgery, Oral Medicine, Oral Pathology and Oral Radiology 122(5): e164.

\section{Your next submission with Juniper Publishers will reach you the below assets}

- Quality Editorial service

- Swift Peer Review

- Reprints availability

- E-prints Service

- Manuscript Podcast for convenient understanding

- Global attainment for your research

- Manuscript accessibility in different formats

( Pdf, E-pub, Full Text, Audio)

- Unceasing customer service

Track the below URL for one-step submission https://juniperpublishers.com/online-submission.php 